ANNOTATIONS.

\title{
The Royal Army Medical Corps
}

Our talented and energetic colleague, Sir James W. Barrett, K.B.E., C.B., C.M.G., of Melbourne, has written a volume ("A Vision of the Possible: what the R.A.M.C. might become," London, 1919), of appreciation and of constructive criticism of the Royal Army Medical Corps. His qualifications for undertaking such a work can scarcely be questioned, for he has had experience in the Australian Army Medical Corps in Egypt as well as in the Royal Army Medical Corps itself in that country. He is now leaving the service and is strongly of opinion that if the traditions of the Corps are to be kept up some of its archaic methods must be modified and provision made for greater flexibility. A service such as Sir James imagines should lead the world in scientific medicine, and he endeavours in the present volume to indicate the lines upon which such an evolution should proceed. That the authorities are in sympathy may be inferred from the fact that they have allowed the book to be published, an attitude for which they are entitled to unstinted praise. The fundamental weakness in the administration appears to be that an officer tends to become what Sir James terms an "office wallah," that is to say, he tries to manage a body of capable men by writing letters to them often from a great distance. The most obvious change in principle is that superiors should fully and in conference discuss important items with their subordinates. Every administrative officer should be provided with an understudy of nearly the same rank as himself, so that one or the other may be constantly travelling through the command. In the higher branches of the Royal Army Medical Corps officers cease to be medical men and scientists and become administrators. It is suggested that there should be three avenues to promotion: (1) As at present, through administrative work; (2) by clinical work alone; and (3) by preventive medicine. As regards promotion, the author praises the system which has been evolved in Australia, where the matter devolves upon a board of three members, one of whom is appointed by the Secretary of State, the second by the Public Service Commissioner, and the third by the class whose members are to be promoted. Under this scheme affairs are not left, as at present, in the hands of a single individual. Sir James holds that medical officers should do medical work, and that many of the duties now discharged in the Army by them could be better done by a sergeantmajor or a lieutenant-quartermaster of the Royal Army Service Corps. It is important that the newly-joined medical officer should be instructed by his seniors as to the necessity of passing on with transferred men proper clinical information respecting their condition. 
Orders should be codified periodically, and issued in printed form to every medical officer in the Army. Another reform advocated is the formation of a board of reference for serious complaints made by a medical officer. Finally, Sir James calls for a Royal Commission, and suggests that a certain number of the medical commissioners should not be Government nominees, but be elected by medical officers who have served for substantial periods abroad. The recommendations of a Royal Commission may be far removed from those put forward by Sir James Barrett, but the author asks that whatever the answer " the issue should not be evaded or camouflaged." We again congratulate the authorities upon allowing so outspoken a book as this to be published. The sign is of good augury for the future of the Royal Army Medical Corps.

\section{Panel Ophthalmic Practice}

There appeared in a recent number of the Lancet an article dealing with the question of Panel Ophthalmic Practice. The author, Dr. Freeland Fergus, holds very strong views on the necessity for a much higher standard of qualification for those who intend to devote themselves to ophthalmology than at present obtains. In this he has our whole-hearted support as numerous recent notes in our pages can testify. When, however, he proposes that all panel patients should be examined by whole-time highlyqualified ophthalmic surgeons at some 800 to 1,000 new centres and that special hospitals should be built to accommodate them we fail to see how the cost could be met. In addition to the money difficulty it would be scarcely possible to find the necessary surgical and nursing staff. We can hardly agree with his suggestion that a competent surgeon could not examine adequately more than three children in the course of two hours. At that rate of work the whole medical profession of the country would hardly suffice for the working of his scheme.

\section{The Teaching and Examination of Medical Students in Ophthalmology}

The General Medical Council have had under consideration the report of the Council of British Ophthalmologists on the teaching of medical students. They have recommended " that every student should be required to attend a course of practical instruction in ophthalmology of not less than ten week's.duration, and that no student should be admitted to the final examination unless he presents a certificate to the effect that he has attended such a course regularly and that his work in connection therewith has 